\title{
PANORAMA DOS ASSENTAMENTOS RURAIS EM SANTA CATARINA
}

\author{
OVERVIEW OF RURAL SETTLEMENTS IN SANTA CATARINA
}

VISIÓN GENERAL DE LOS ASENTAMIENTOS RURALES EN SANTA CATARINA

\author{
Danieli Cristina de Souza ${ }^{1}$ \\ https://orcid.org/0000-0003-2185-7823 \\ Dimas de Oliveira Estevam ${ }^{2}$ \\ https://orcid.org/0000-0002-8116-2209
}

Submissão: 30/11/2020 / Aceito: 23/02/2021 / Publicado: 31/03/2021.

\begin{abstract}
Resumo
O presente artigo tem por objetivo traçar um panorama da distribuição territorial dos assentamentos rurais nas mesorregiões catarinenses e identificar o acesso a políticas públicas, como o Programa de Aquisição de Alimentos (PAA) e a Assistência Técnica e Extensão Rural (ATER), pelos assentados. A pesquisa tem uma abordagem exploratória descritiva sobre políticas públicas e reforma agrária, juntamente com os dados da Diretoria de Obtenção de Terras e Implantação de Projetos de Assentamento. Como resultado tem-se 162 projetos, com 5.033 famílias assentadas, distribuídos nas seis mesorregiões do Estado. Constataram-se 138 contratos de ATER e 243 de PAA distribuídos em $21,6 \%$ dos assentamentos. As mesorregiões da grande Florianópolis e do sul catarinense contam com a menor quantidade de projetos de assentamentos, mas possuem maior média de área por família e nenhum projeto contemplado com a ATER e o PAA. Conclui-se que há uma distribuição desigual no território catarinense em relação ao acesso às políticas públicas (ATER e PAA) instigada especialmente pelas pluralidades das comunidades assentadas e pelas diretrizes institucionais das modalidades de projetos e desses programas estudados.
\end{abstract}

Palavras-chave: Questão Agrária. Assentamentos Rurais. Extensão Rural.

\begin{abstract}
This article aims to provide an overview of the territorial distribution of rural settlements in the Santa Catarina mesoregions and to identify access to public policies, such as the Food Acquisition Program (PAA) and Technical Assistance and Rural Extension (ATER), by the settlers. The research has an exploratory, descriptive approach on public policies and land reform, together with data from the Directorate for Land Procurement and Settlement Projects. As a result, 162 projects were carried out, with 5,033 families settled, distributed in the six mesoregions of the State. 138 ATER contracts and 243 PAA contracts were found, distributed in $21.6 \%$ of the settlements. The mesoregions of greater Florianópolis and southern Santa Catarina have the least amount of settlement projects, but with the highest average area per family and no project contemplated with ATER and PAA. It is concluded that there is an uneven distribution in the territory of Santa Catarina, in relation to access

1 Mestranda do Programa de Pós-Graduação em Desenvolvimento Socioeconômico da Universidade do Extremo Sul Catarinense (UNESC). E-mail: dcs@unesc.net

2 Doutor em Sociologia Política pela Universidade Federal de Santa Catarina (2009). Pesquisador e Docente Permanente (Mestrado e Doutorado) do Programa de Pós-Graduação em Desenvolvimento Socioeconômico (PPGDS/Unesc).

E-mail: doe@unesc.net
\end{abstract}


to public policies (ATER and PAA). Specially instigated by the pluralities of the settled communities, the institutional guidelines of the modalities of projects, and of these studied programs. Keywords: Agrarian Question. Rural Settlements. Rural extension.

\section{Resumen}

Este artículo tiene como objetivo brindar un panorama de la distribución territorial de los asentamientos rurales en las mesorregiones de Santa Catarina e identificar el acceso a políticas públicas, como el Programa de Adquisición de Alimentos (PAA) y la Asistencia Técnica y Extensión Rural (ATER), por parte de los pobladores. La investigación tiene un enfoque exploratorio y descriptivo sobre políticas públicas y reforma agraria, junto con datos de la Dirección de Proyectos de Adquisición y Asentamiento de Tierras. Como resultado, se llevaron a cabo 162 proyectos, con 5.033 familias asentadas, distribuidas en las seis mesorregiones del Estado. Se encontraron 138 contratos ATER y 243 contratos PAA, distribuidos en el 21,6\% de las liquidaciones. Las mesorregiones del Gran Florianópolis y el sur de Santa Catarina tienen la menor cantidad de proyectos de asentamiento, pero con el área promedio más alta por familia y ningún proyecto contemplado con ATER y PAA. Se concluye que existe una distribución desigual en el territorio de Santa Catarina, en relación al acceso a las políticas públicas (ATER y PAA). Especialmente instigados por las pluralidades de las comunidades asentadas, los lineamientos institucionales de las modalidades de proyectos y de estos programas estudiados.
\end{abstract}

Palabras chave: Cuestión agraria. Asentamientos rurales. Extensión rural.

\title{
INTRODUÇÃO
}

A reforma agrária, no Brasil, tem sido realizada entre avanços, estagnação e retrocessos. A estrutura fundiária brasileira é constituída por vasta diversificação em termos de implantação de novos assentamentos, em especial pelo número de projetos, pelas territorialidades distintas e por seus enquadramentos nas modalidades determinadas pelo Instituto Nacional de Colonização e Reforma Agrária (INCRA).

A organização e estrutura fundiária consiste não apenas nos aspectos da concentração de terra, do ordenamento e dos modos de ocupação; ela se insere no contexto das relações políticas, econômicas e socioculturais que representam o domínio de disputa de determinado território (FERNANDES, 2001), o que significa um processo envolvendo trocas, mediações, contradições, articulações, conflitos, movimentos e transformações (MARTINS, 1981). É um campo material e simbólico, o qual representa os processos compostos por interesses e disputas.

A constituição socioprodutiva dos assentamentos rurais exige a compreensão da política de reforma agrária vigente, mas isso está além do caráter exclusivo de distribuição de terras, está inserido em um âmbito mais amplo e como parte do complexo de lutas sociais, econômicas, políticas, ideológicas e ambientais pela terra (CARVALHO, 2013). Trata-se de adentrar a 
perspectiva de manutenção das famílias assentadas em dimensões nas quais se sobressai o fato de criação, reconhecimento e consolidação de projetos de assentamentos pelo Estado.

A dinâmica de grande parcela dos assentamentos está marcada pela superação dos desafios ante áreas improdutivas, delongas com a regularização fundiária, precariedade no acesso a bens e serviços básicos (água, energia, saúde, educação, infraestrutura viária), tornando-se ainda mais significativa a acessibilidade a assistências sociais e produtivas, como a extensão rural e os programas governamentais que fomentam o desenvolvimento socioterritorial.

Sobre as singularidades das modalidades de projetos constituídos pelo INCRA, o que está presente é a representação simbólica da conjuntura histórica e social que os levou até a inserção coletiva ou individual dos sujeitos desses assentamentos, a experiência da conquista do território e as oportunidades que se distinguem da trajetória até então vivenciada, assim como a busca de um ponto de chegada comum na expectativa de autonomia e das possibilidades de acessos ao conjunto de políticas e de visibilidades produtivas e socioeconômicas inacessíveis na condição anterior (LEITE, 2004, 2012).

Ao reconhecer a organização política e as racionalidades de interesses socioeconômicos entre as concepções institucionais dos órgãos públicos e as das famílias, torna-se mais realista a interpretação dos modos de vida das comunidades (NEVES, 1997). Para isso, em 1998, a FAO (Organização das Nações Unidas para a Alimentação e a Agricultura) e o INCRA realizaram um estudo para identificar os aspectos que dificultavam o desenvolvimento dos assentamentos. Entre os mais mencionados estavam a infraestrutura básica, as dificuldades de acesso ao crédito e à assistência técnica, a gestão, a organização e a comercialização (GUANZIROLI et al., 1999).

Nesse sentido, o desafio está na inserção de políticas públicas capazes de incorporar as peculiaridades do espaço rural e assim oportunizar acessos equitativos a bens e a serviços em prol da melhoria social e produtiva das famílias que estejam vinculadas diretamente à reflexão quanto ao processo histórico de interferências e resistências e aos aspectos jurídicos e sociopolíticos presentes na questão agrária. E, também, que possam remeter a caminhos a serem percorridos nos programas governamentais e nas políticas públicas, os quais atendam às expectativas das famílias envolvidas.

A Assistência Técnica e Extensão Rural (ATER), com a promulgação da Lei no ${ }^{\circ}$ 12.188, de 11 de janeiro de 2010, que instituiu a Política Nacional de Assistência Técnica e Extensão Rural para a Agricultura Familiar e Reforma Agrária (PNATER), considera o seguinte:

Assistência Técnica e Extensão Rural - ATER: serviço de educação não formal, de caráter continuado, no meio rural, que promove processos de gestão, produção, beneficiamento e 
comercialização das atividades e dos serviços agropecuários e não agropecuários, inclusive das atividades agroextrativistas, florestais e artesanais. (BRASIL, 2010, p. 1).

Assim, entre as bases de princípios e finalidades da legislação estão a valorização e os saberes dos assentados da reforma agrária, dos povos indígenas, dos remanescentes de quilombos, dos povos tradicionais e da agricultura familiar por meio de metodologias participativas e multidisciplinares, propiciando o desenvolvimento rural alinhado à sustentabilidade, à conservação e à recuperação dos agroecossistemas e da biodiversidade, bem como o apoio à integração de mercado em prol do aumento da renda pela agregação de valor da produção em vista da soberania e da segurança alimentar. Em suma, a base da extensão rural e da assistência técnica está “[...] diversificada, apropriada e contextualizada à realidade do meio rural brasileiro" (BRASIL, 2010, p.1).

Ao encontro das principais ações estatais que fomentam as políticas agrárias alinhadas às políticas sociais se destaca um dos principais programas que está sendo executado nos estados e municípios brasileiros, em parceria com o Ministério da Cidadania e pela Companhia Nacional de Abastecimento (Conab), ou seja, o Programa de Aquisição de Alimentos (PAA), que foi institucionalizado no art. 19 da Lei $n^{\circ}$ 10.696, de 02 de julho de 2003, alterado em outubro de 2011 pela Lei $\mathrm{n}^{\circ} 12.512$ e atualmente em vigência pelo Decreto $\mathrm{n}^{\circ} 7.775$, de 4 de julho de 2012 , o qual estabelece, entre as finalidades e diretrizes do PAA,

I - incentivar a agricultura familiar, promovendo a sua inclusão econômica e social, com fomento à produção com sustentabilidade, ao processamento, à industrialização de alimentos e à geração de renda; II - incentivar o consumo e a valorização dos alimentos produzidos pela agricultura familiar; III - promover o acesso à alimentação, em quantidade, qualidade e regularidade necessárias, às pessoas em situação de insegurança alimentar e nutricional, sob a perspectiva do direito humano à alimentação adequada e saudável; IV promover o abastecimento alimentar por meio de compras governamentais de alimentos, inclusive para prover a alimentação escolar e o abastecimento de equipamentos públicos de alimentação e nutrição nos âmbitos municipal, estadual, distrital e federal, e nas áreas abrangidas por consórcios públicos; V - constituir estoques públicos de alimentos produzidos por agricultores familiares; VI - apoiar a formação de estoques pelas cooperativas e demais organizações formais da agricultura familiar; VII - fortalecer circuitos locais e regionais e redes de comercialização; VIII - promover e valorizar a biodiversidade e a produção orgânica e agroecológica de alimentos, e incentivar hábitos alimentares saudáveis em nível local e regional; e IX - estimular o cooperativismo e o associativismo. (BRASIL, 2012, p. 1).

Na essência, oportuniza à agricultura familiar dinamizar suas formas de comercialização, instigando, principalmente, a organização coletiva para a inserção ao mercado. Em 2009, por meio da Lei ${ }^{0} 11.947$, determinou-se que:

Do total dos recursos financeiros repassados pelo FNDE, no âmbito do PNAE, no mínimo $30 \%$ (trinta por cento) deverão ser utilizados na aquisição de gêneros alimentícios diretamente da agricultura familiar e do empreendedor familiar rural ou de suas 
organizações, priorizando-se os assentamentos da reforma agrária, as comunidades tradicionais indígenas e comunidades quilombolas. (BRASIL, 2009, p. 2).

Diante desse cenário, mesmo que por maneiras separadas, mas complementares à vigência de um programa de extensão rural e assistência técnica ativo nos assentamentos e nas comunidades rurais, culminando na oportunidade dos princípios e da viabilização legais e administrativos do PAA e do PNAE, traz a expectativa, de certo modo, ao acesso mais equitativo, promovendo não apenas a comercialização, mas a visibilidade da diversidade (sociocultural concretizada no modo e nos aspectos produtivos) presente. Instiga também os possíveis cenários entre viabilidade e entraves sobre a efetiva materialização em projetos de assentamento.

Esse ponto se atrela em virtude de, em certa medida, ocorrer nele uma discussão sobre a reforma agrária. Ele se concentra em aspectos jurídicos, políticos e ideológicos, o que limitou a abertura de debates sobre aspectos e desdobramentos de demandas e especificidades dos projetos de assentamentos constituídos. Desse modo, o que se observa na conjuntura presente é que se focou mais nos aspectos quantitativos do que nos qualitativos no processo de criação para a consolidação desses assentamentos.

Em outras palavras, deu-se relevância a estudos que abarcam as condições e os graus de interferências e coparticipações do Estado ante as fases de implementação, trazendo à luz a inferência da institucionalização do reconhecimento pelo INCRA da factibilidade dos resultados sociais, por exemplo, ao acesso de políticas agrárias e sociais às famílias assentadas. Isso tudo revela a "ponte" entre as competências do órgão, que se insere historicamente em legislações, a saber: Estatuto da Terra, Lei n ${ }^{\circ}$ 4.504, de 30 de novembro de 1964; Política Agrícola e Fundiária contida na Constituição Federal de 1988; Regularização das diretrizes para a Reforma Agrária, Lei n 8.629, de 25 de fevereiro de 1993. Referidas legislações designam-no a criar possibilidades de reconhecer um projeto e consolidá-lo dentro do programa de reforma agrária e demarcam a presença Estatal na gestão e política fundiária na construção da autonomia das famílias assentadas ante as demandas e peculiaridades de cada projeto.

Diante do exposto, o presente estudo tem por objetivo traçar um panorama da distribuição territorial dos assentamentos rurais nas mesorregiões catarinenses e identificar o acesso a políticas públicas, como ATER e PAA, pelas famílias assentadas, dialogando sobre os elementos estruturais da questão agrária e a implementação das modalidades de projetos de assentamentos vinculados ao INCRA.

O artigo está organizado da seguinte maneira: além desta parte introdutória, trata-se da questão da reforma agrária para além da condicionante terra, de modo a incluir ao debate a 
concepção e as inserções das modalidades de projetos de assentamentos instituídos pelo INCRA. Depois, são expostos os procedimentos metodológicos que compõem as fontes e os critérios de análise deste estudo para o panorama dos projetos de assentamentos constituídos em Santa Catarina. $\mathrm{Na}$ sequência, os dois próximos tópicos abordam as conjunturas que demarcam a distribuição territorial, a caracterização das modalidades e o acesso das famílias assentadas ao PAA e à ATER no Estado, seguidos das considerações finais.

\section{A QUESTÃo AGRÁRIA E A REFORMA AGRÁRIA NO BRASIL}

A questão agrária (QA) no País é tratada por diferentes abordagens. Para Fernandes (2001, p. 23), como “[...] o movimento do conjunto de problemas relativos ao desenvolvimento da agropecuária e das lutas de resistência dos trabalhadores, que são inerentes ao processo desigual e contraditório das relações capitalistas de produção". Sendo definida de diversas formas como a concentração da propriedade da terra vinculada ao desenvolvimento produtivo para explicar como se desenvolvem as relações sociais na organização da produção rural, para explicar como as pessoas vão se apropriando da utilização da natureza (terra) e como vai ocorrendo a ocupação no território, a QA é utilizada também para explicar a evolução da luta política, o controle dos territórios e a posse da terra (STÉDILE, 2005). Neste trabalho, a QA visa compreender como se organizam a posse, a propriedade e o uso da terra no País sob a ótica das modalidades de projetos de assentamentos do Instituto Nacional de Colonização e Reforma Agrária (INCRA).

A trajetória da experiência brasileira de Reforma Agrária (RA) apresenta fases intermitentes, geralmente malsucedidas, como foi a Lei n⿳ำ 4.504, de novembro de 1964, chamada "Estatuto da Terra". Essa legislação teve dificuldades e reveses que praticamente inviabilizaram sua implantação. Com isso, abdicou-se de um sistema mais justo de propriedade, de maneira que, completada por crédito oportuno e adequado, assistência técnica, comercialização e distribuição de seus produtos, pudesse constituir, para o trabalhador rural, a base de sua estabilidade econômica e de seu bem-estar e a garantia de sua liberdade e dignidade (NEVES, 1997).

Nesse período, as tentativas de RA encaminhadas pelo Estado foram poucas e revelaram-se infrutíferas, pois criaram mais expectativas do que resultados concretos. Com o advento da Nova República, foi lançando o Plano Nacional de Reforma Agrária (PNRA), que aprovou os chamados Programas Regionais para a implantação da RA nos Estados. Contudo, muitos fatores bloquearam a execução do PNRA, como o poder de veto dos grandes proprietários de terras, persistentes no 
mundo agrário brasileiro. Os assentamentos implementados tiveram problemas, pois os lotes de terra foram entregues aos agricultores sem as ações complementares necessárias de apoio à regularização, produção e estruturação das propriedades.

Tais questões, quando minimizadas, são consideradas essenciais na viabilização das unidades de produção e na organização social e familiar para que tenham possibilidades de acesso a políticas públicas e a mercados locais e regionais, bem como para que construam condições mínimas de permanência e desenvolvimento comunitário.

Os estudos sobre assentamentos, em nível nacional, apresentam as condições que influenciam as continuidades das famílias assentadas quando percorrem um quadro limitante e/ou potencializador sob a presença ou não de investimentos em infraestruturas sociais e produtivas (BERGAMASCO, 1997; FERREIRA, 1994; GUANZIROLI et al., 1999). Entre os aspectos desafiadores aos beneficiários, destacam-se: a localização do assentamento aos centros comerciais, educacionais e de saúde e/ou as péssimas condições das estradas; as terras com baixa produtividade (problemas geológicos ou de acesso à água); e a inexistência ou ineficiência de assistência técnica.

Com a Constituição Federal (BRASIL, 1988), ficou estabelecida a função social da terra. Nesse sentido, entende-se que ela deve ser destinada ao bem comum de todos os cidadãos. Se ela se concentra demasiadamente nas mãos de poucos, torna-se antissocial, injusta, ilegal e desumana. A distribuição da terra de forma mais equilibrada é uma questão de justiça social e de humanidade. Para o processo de RA ser efetivo, é preciso se despir de juízos de valores e colocar a questão da posse da terra para além do debate de ser contra a RA ou a favor dela.

De maneira geral, a concentração de terras no Brasil tem aumentado ao longo do tempo com a expansão da fronteira agrícola, principalmente em regiões da Amazônia e do Cerrado, além do seu valor monetário crescente em muitas regiões, obrigando os agricultores menos capitalizados a deixarem suas terras. Em todo o País, tem-se assistido ao aumento das queimadas e dos impactos ambientais, às invasões de terras indígenas, ao crescimento dos conflitos e ao aumento da violência, dentre outros problemas. Portanto, a questão da terra expõe seu lado mais controverso e sua desigual distribuição com seus diversos grupos de interesses: boias-frias, indígenas, posseiros, quilombolas e pequenos proprietários de um lado; grileiros, grandes proprietários, garimpeiros e multinacionais de outro lado.

Os impasses agrários e agrícolas no cenário nacional, segundo Mattei (2014), estão instituídos sobre a vertente dos desequilíbrios sociais, que enseja um processo de reforma agrária potencializador, de caráter regional, com um efetivo projeto que trate das injustiças sociais por meio de "profundas mudanças". Ou seja, necessidade de intensificações mais sociais, demarcações 
fundiárias mais racionais e democráticas, promoção tecnológica e produtiva, ecológica e sociopolítica.

A concepção de RA para o Estado brasileiro está ligada ao projeto de assentamento, compreendido como "[...] um conjunto de ações planejadas e desenvolvidas em área destinada à Reforma Agrária, de natureza interdisciplinar e multissetorial, integradas ao desenvolvimento territorial e regional” (BRASIL, 2004, p. 148), tendo como base as características na perspectiva do cumprimento da função social da terra e toda a estrutura relacionada à plena execução.

Diante dessas e de outras observâncias, o INCRA classifica seus projetos de assentamentos em duas modalidades principais. A primeira é a dos projetos de assentamento, que são criados por meio da obtenção de terras pelo próprio órgão, na forma tradicional, denominados Projetos de Assentamento (PAs). Os ambientalmente diferenciados são chamados Projeto de Assentamento Agroextrativista (PAE), Projeto de Desenvolvimento Sustentável (PDS), Projeto de Assentamento Florestal (PAF) e Projeto Descentralizado de Assentamento Sustentável (PDAS). Há, ainda, possíveis denominações que deixaram de ser criadas a partir da década de 1990 e que ainda constam em seus relatórios como controle de fases de suas implementações.

Já a segunda modalidade se enquadra em projetos de assentamentos reconhecidos pelo INCRA, criados por outras instituições governamentais para acesso às políticas públicas do Plano Nacional de Reforma Agrária, a saber: Projeto de Assentamento Estadual (PE) ou Municipal (PAM); Reservas Extrativistas (RESEX); Território Remanescente Quilombola (TRQ); Reconhecimento de Assentamento de Fundo de Pasto (PFP); Reassentamento de Barragem (PRB); Floresta Nacional (FLONA) e Reserva de Desenvolvimento Sustentável (RDS).

As modalidades, além de ofertarem uma classificação quanto às características das comunidades, possibilitam a gestão quanto às responsabilidades das fases de implementação dos referidos projetos, haja vista que quando se trata de projetos da primeira modalidade, assentamentos implementados pela "forma tradicional", o INCRA viabiliza todas as etapas técnicas e administrativas (local, escolha de famílias, infraestrutura) por meio da legislação vigente. No caso de assentamentos criados por "outras instituições governamentais", cada submodalidade integrante desse grupo possui suas próprias diretrizes, desde a obtenção da terra até o assentamento consolidado.

A questão central é não se reduzir à compreensão do termo assentamento basicamente pelas glebas agrícolas instaladas pelo INCRA ou ao vínculo direto de determinado movimento social. É preciso considerar os sujeitos presentes na materialização desses projetos de tal modo que se perceba a diversidade das lutas existentes em comum com o acesso e direito a terra, uma expressão política 
e socioterritorial, que inclui o caráter de moradia e produtivo aos aspectos culturais e identitários dos contextos históricos, subjetivos desses sujeitos e de suas coletividades.

\section{Procedimentos metodológicos}

A pesquisa classifica-se como qualitativa e descritiva e propõe-se a organizar e a apresentar a distribuição territorial dos projetos de assentamentos no estado de Santa Catarina (FLICK, 2009) ao se complementar do caráter explicativo e contribuir para a classificação ante as características e especificidades que categorizam os assentamentos nas modalidades de projetos do INCRA, demandando ação indutiva e analítica diante do grau de inserção dos projetos de assentamentos ao PAA e à ATER (GIL, 2014; MARTINS, 2004). Para tanto, utilizou-se do aparato teórico, sendo priorizadas as fontes produzidas pelo Estado sobre a questão agrária e a reforma agrária no Brasil, perpassando pelos aspectos das políticas públicas agrícolas, com destaque ao PAA e à ATER em assentamentos rurais.

Ao realizar a divisão mesorregional dos projetos de assentamentos em Santa Catarina, recorreu-se à base de dados da Diretoria de Obtenção de Terras e Implantação de Projetos de Assentamento do INCRA (DT/INCRA), no Sistema de Informação de Projetos de Reforma Agrária (SIPRA), contabilizando o período total de disponibilidade sobre projetos de assentamentos cadastrados no órgão, extraído em março de 2020, incluindo modalidade, data de criação, localização, número de famílias assentadas e área disponibilizada, a análise do período de reconhecimento pelo órgão competente e, quando possível, também perceber a dinâmica atemporal do processo social, político e administrativo entre comunidade e instituição.

Com referência aos dados, registra-se a limitação em relação a eles quanto à inserção de famílias assentadas beneficiadas em programas como o PAA e a ATER. Diante do exposto, foram utilizadas as informações do ano de 2017, contidas na mesma plataforma supracitada da Superintendência Regional, editadas pelo INCRA em 2018, sendo estes os últimos dados disponibilizados pelo órgão quanto ao acesso a políticas públicas como o PAA e a ATER aos assentados.

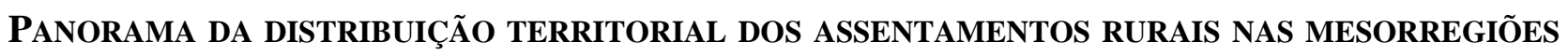 CATARINENSES}


A estrutura fundiária catarinense apresenta características similares às de outros estados brasileiros, resultado de uma distribuição desigual a partir do processo de interiorização da colonização do País. Santa Catarina se caracteriza com estrutura fundiária distinta entre as mesorregiões, com forte presença de pequenas propriedades e com a presença de grandes latifúndios nas regiões do Planalto e Meio-Oeste.

Como resultados da pesquisa, em nível nacional, com base no relatório da Diretoria de Obtenção de Terras e Implantação de Projetos de Assentamento do INCRA, foram encontrados registros de assentamentos constituídos desde a década de 1930 até o ano de 2019. Em Santa Catarina, o primeiro projeto implementado foi no ano de 1983. Contudo, constatou-se a existência de diferentes datas e ocorrências quanto à inserção das famílias em processos de ocupação, acampamento e assentamento. Assim como, para o órgão, uma variação temporal entre reconhecimento, obtenção e ato de criação do projeto.

Como nem todo projeto envolve diretamente uma inserção coletiva dos movimentos sociais, os espaços e transições de lutas e resistências para a formação do assentamento resultam em demarcações e organizações diferenciadas, iniciando-se, assim, muitas vezes, como é apontado por Fernandes (2012), pelo acampamento, que é considerado o espaço de luta e resistência no processo de espacialização e territorialização da luta pela terra, sendo caracterizante a organização dos semterra na demarcação do território contra a grande propriedade e em defesa do direito a terra como elemento de justiça social.

É importante a menção do significado de acampamento, visto que nos relatórios dos projetos de assentamentos do INCRA o órgão apresenta uma "data de criação", a qual se refere à criação de uma ação no referido território, que futuramente será reconhecido pela entidade como assentamento. Essa ação pode ser um acampamento iniciado pelos movimentos sociais e/ou uma ação estatal para beneficiar famílias em áreas desapropriadas pelo Estado.

O processo de assentamento, conforme Saquet (2009), efetiva-se de maneira múltipla e híbrida, envolvendo dimensões condicionadas pelos modelos de projetos constituídos pelo Estado, mas essencialmente as relações que se constroem nesse espaço, seja ele desde a sua gênese de lutas e resistências ou determinado pelas ações jurídicas, administrativas e políticas estatais e de governo. Diante desses aspectos, trata-se no órgão pela "data de reconhecimento" do projeto de assentamento, data que serviu de base para a captação dos dados deste estudo.

Os resultados da pesquisa apontam que no território brasileiro existem 9.436 assentamentos, com 970.262 famílias assentadas (BRASIL, 2020). Em Santa Catarina, foram registrados 162 projetos, o que representa $1,72 \%$ dos assentamentos no Brasil, com 5.033 famílias assentadas, 
representado 0,52\% das famílias assentadas no País, distribuídos nas seis mesorregiões do Estado. Conforme a Figura 1, a mesorregião do Oeste possuí 94 projetos de assentamentos, beneficiando 3.516 famílias, seguida pela mesorregião Serrana, com 33 projetos, 768 famílias; Norte, com 26 projetos, 526 famílias; vale do Itajaí, com seis projetos e 163 famílias; grande Florianópolis, com dois projetos e 19 famílias; e sul do Estado, com um projeto e 41 famílias.

\section{Figura 1 - Panorama dos assentamentos rurais em Santa Catarina}

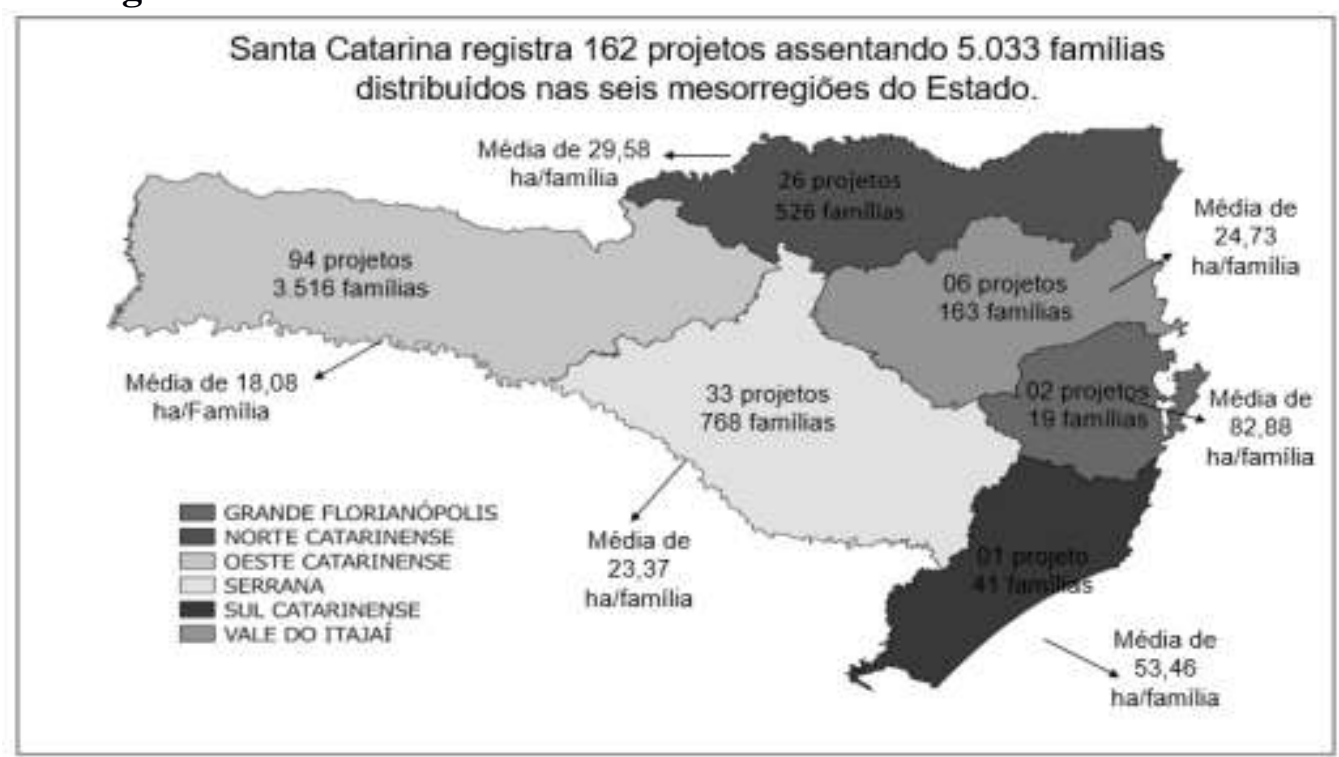

Fonte: Relatórios da Diretoria de Obtenção de Terras e Implantação de Projetos de Assentamento (BRASIL, 2020). Adaptada pelos autores (2020).

Com relação à modalidade dos projetos cadastrados, o Estado conta com 142 (87,65\%) na modalidade I e 20 (12,35\%) na modalidade II. Constatou-se que 141 (87,04\%) desses projetos estão inseridos como Projeto de Assentamento Federal (PA), sendo que 104 (73,76\%) foram registrados entre os anos de 1983 a 2000 e 37 (26,24\%) entre 2001 a 2015; 16 projetos (9,87\%) foram registrados como Reassentamento de Barragem (PRB), concentrando seus atos de criação entre os anos de 2007 e 2008; três (1,85\%) como Projeto de Assentamento Estadual (PE), com registro no INCRA nos anos de 1992,1995 e 1996.

Na modalidade de Projeto de Assentamento Estadual (PE), existem indícios de que eles foram criados na década de 1980, em nível federal, com a interferência da Superintendência do Desenvolvimento da Região Sul (SUDESUL), sendo inseridos em projetos integradores, cujas famílias foram vinculadas ao Programa Fundos de Terras do Estado de Santa Catarina. Com a extinção da autarquia, em 1990, a União repassou-os para o Estado, via decreto, nos anos seguintes, por isso a menção no relatório do INCRA da consolidação deles apenas entre os anos de 1992 e 
1996. Ainda sobre as modalidades, constatou-se o reconhecimento de um $(0,62 \%)$ projeto no ano de 2011 como Reservas Extrativistas (RESEX) e um (0,62\%) como Projeto de Desenvolvimento Sustentável (PDS), o qual foi criado em 2017.

Figura 2 - Modalidades de projetos de assentamentos do INCRA e classificações em Santa Catarina

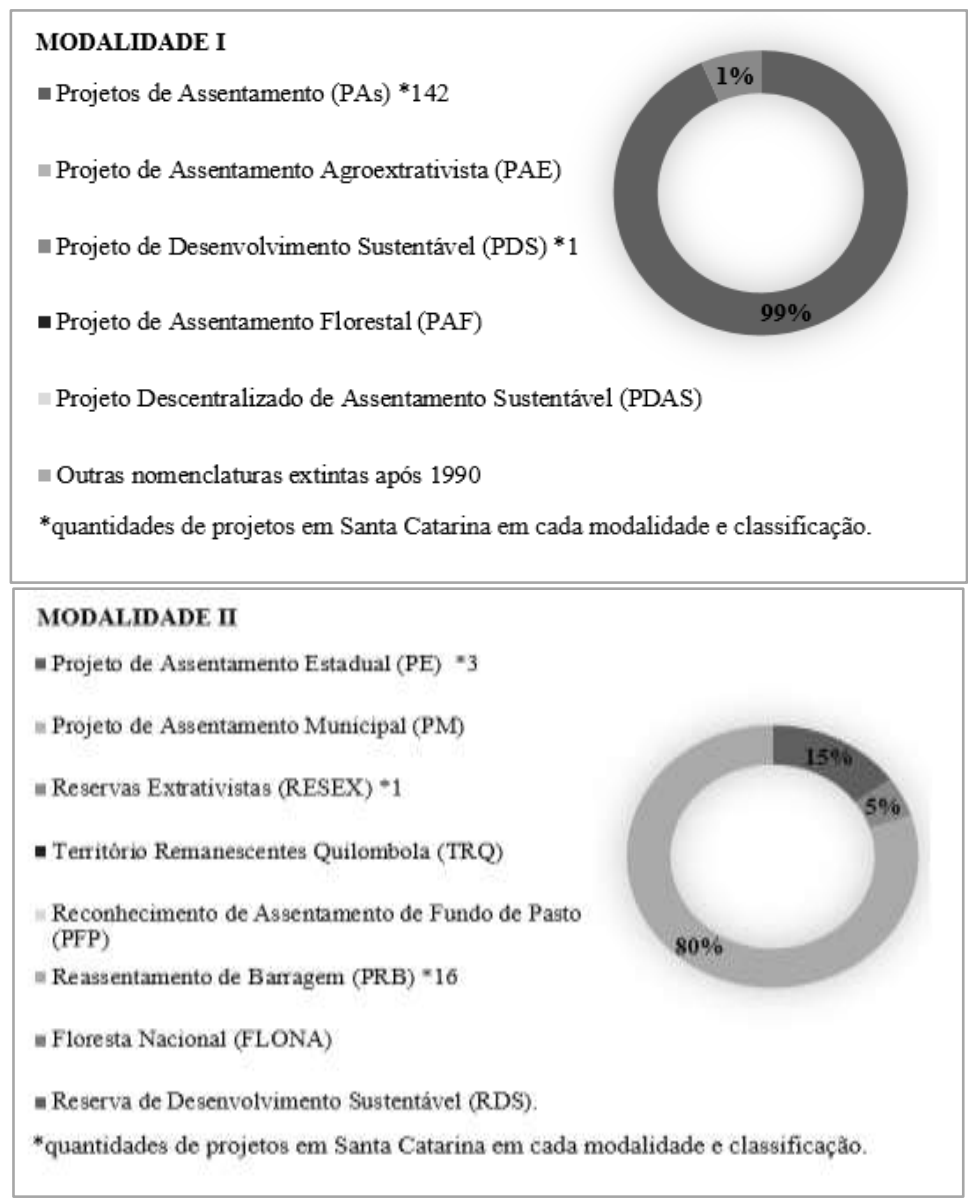

Fonte: Relatórios da Diretoria de Obtenção de Terras e Implantação de Projetos de Assentamento (BRASIL, 2020). Adaptada pelos autores (2020).

Os significados dessas caracterizações são os mais variados e complexos ante as realidades de cada projeto reconhecido pelo órgão. Ao estabelecer as modalidades aos projetos, valorizam as comunidades, dando visibilidade às suas estruturas intrínsecas, haja vista que se espera que a especificidade sociocultural seja considerada. Por outro lado, inferem nas dinâmicas de acessos básicos às infraestruturas, assistenciais (saúde, educação, moradia, lazer e outras) e de políticas públicas agrícolas e agrárias.

As distinções quanto ao objetivo que concretiza o acesso da terra e discorre na vivência social da comunidade assentada se baseiam, entre outros fatores, como nas ocorrências de intervenções 
externas, na história sociopolítica individual e coletiva, que culmina na organização comunitária e nas iniciativas e oportunidades de estilos produtivos (MEDEIROS et al., 1994).

Essas intervenções integram a dinâmica de inclusão na pauta de atuação de órgãos públicos, com enfoque no INCRA, refletindo na caracterização do projeto de assentamento reconhecido de acordo com as diretrizes básicas de cunho responsivo do órgão - disponibilidade à concessão de terras, condições para uso e incentivo à organização -, alinhando-se a representatividade heterogênica ao tocante das formas socioculturais e de geração e manutenção de renda de cada comunidade.

Como apontado por Wanderley (2000), é esse tecido social que promove a constituição de projetos em uma dinâmica de pertencimento em perspectivas e espaço de trabalho e de vida das famílias agricultoras e assentadas de tal modo, que a inserção em um determinado projeto, o qual está representado na partida da sua intitulação de caracterização do grupo pertencente, tende a promover ações mais diretivas, focalizadas, sobretudo a ressignificação do rural.

A caracterização da modalidade e a data de criação revelaram que assim como os primeiros projetos cadastrados estavam ligados majoritariamente à modalidade de reconhecimento tradicional (PA) de projeto de assentamento pelo INCRA, os últimos também representam alguma movimentação em virtude de novas agendas governamentais ante as demandas sociais, ambientais e econômicas das conjunturas nacionais, que deram concretude a avanços de atos políticos e legislatórios de cada período. Por exemplo, em Santa Catarina, os Projetos de Reassentamento de Barragens a partir dos anos 2000 e os Projetos de Desenvolvimento Sustentável em 2014, e mesmo em todo o território brasileiro, com as modalidades de assentamentos ambientalmente diferenciados que envolvem comunidades quilombolas, extrativistas, das florestas, os quais, mesmo com problemas de longa data e debates recorrentes nas populações, são recentes na abordagem prática e administrativa de órgãos, instituições e agentes públicos.

Ainda sobre as modalidades, importante destacar que os projetos que se enquadram na modalidade II, pelo fato de o INCRA ser responsável pelo reconhecimento e não inferir diretamente em conjunturas como infraestrutura e de viabilidade da terra, podem influenciar os aspectos de regularização fundiária e de condições básicas de reprodução social. Com isso, fica evidenciada a importância da participação do Estado para consolidar o reconhecimento identitário de determinadas populações, instigando as possibilidades de inserções em programas governamentais e em políticas públicas.

Nessa perspectiva, para estudos e análises dos assentamentos rurais, significa ampliar o cânone da problemática, estabelecendo ligações sobre fatos, sujeitos e espaço construído ou 
condicionado, compreendendo a QA em várias estruturas, como formação territorial, regularização fundiária, relações estabelecidas pelo conjunto burocrático e técnico institucionalizado, elementos heterogênicos e intrínsecos do grupo de assentados em suas respectivas regiões, inserção e manutenção de extensão rural em condições que alinhem o processo produtivo e demandas básicas sociais das famílias assentadas. Para tanto, a efetiva reforma agrária pautada no direito, na justiça e nas políticas agrárias sobressai no conceito institucionalizado.

\section{O ACESSO A POlíticas Públicas como ATER E PAA nOS ASSENTAMENTOS RURAis de SANTA Catarina}

Em Santa Catarina, a partir da Lei $n^{\circ}$ 12.188/2010, a inserção da Assistência Técnica e Extensão Rural (ATER) em assentamentos de reforma agrária no Estado catarinense entre os anos de 2012-2017, segundo o estudo realizado por Louzada (2020), possibilitou maior celeridade na prestação de serviços de ATER, abarcando, por meio de metodologias de extensão rural participativa, um atendimento direcionado às possibilidades técnicas e às necessidades das famílias de tal modo, que durante o período de análise foi constatada a estruturação da atuação dos profissionais de ATER em dois grandes "núcleos operacionais" com intervenções administrativas nos termos contratuais, implicando na melhor operacionalização ante as demandas das comunidades inseridas nos respectivos contratos (LOUZADA, 2020).

Ao analisar as famílias e os assentamentos que constam em contratos de Assistência Técnica e Extensão Rural (ATER) em nível estadual, foram contemplados no ano de 2017, com divulgação oficial pelo INCRA em 2018, 138 assentamentos, sendo que apenas um está classificado como Projeto de Reassentamento de Barragem (PRB), enquanto os demais 137 (99,3\%) são Projetos de Assentamentos (PA) que correspondem ao atendimento de 4.912 famílias. Contudo, mesmo havendo presença em 100\% dos assentamentos do vale do Itajaí, em 97,9\% dos assentamentos do Oeste, em 51,5\% dos da mesorregião Serrana e em 14,2\% dos do Norte, os assentamentos da grande Florianópolis e do Sul não registraram atendimentos e assentamentos do Norte e do vale do Itajaí, apresentando mais contratos do que famílias assentadas.

Com a promulgação da Lei $\mathrm{n}^{\circ} 12.188$, que instituiu a Política Nacional de Assistência Técnica e Extensão Rural para a agricultura familiar e reforma agrária (PNATER), para se enquadrar como beneficiário, é necessário que o membro familiar tenha a Declaração de Aptidão ao Programa Nacional de Fortalecimento da Agricultura Familiar (DAP) ou constar na Relação de Beneficiário (RB), homologada no Sistema de Informação do Programa de Reforma Agrária (SIPRA). No caso 
do SIPRA, é preciso que o projeto de assentamento esteja com o processo de cadastro das famílias e de suas áreas demarcadas. Importante mencionar que, nesse sentido, existem aspectos temporais presentes entre as faces de implementação de cada projeto, por exemplo, sobre os projetos de Florianópolis e do Sul, que não registraram atendimentos, existem as suas peculiaridades.

No que se refere ao caso de Florianópolis, caracteriza-se como assentamento de Reserva Extrativista devido às suas características específicas quanto ao modo de renda das famílias e às questões ambientais nesse modelo de assentamento, sendo necessários estudos aprofundados sobre a ausência de atendimento. Em relação ao assentamento do Sul, que conta com 41 famílias assentadas, evidencia-se que sua criação foi na década de 1980, reconhecida pelo INCRA em 1995, sendo suas famílias cadastradas no SIPRA em 2018. Este segundo exemplo revelou os desajustes presentes no processo de criação e reconhecimento pelo órgão, já que estamos tratando de um período temporal significativo para as famílias se enquadrarem formalmente - como no SIPRA para aderirem a determinadas políticas e a programas governamentais tanto para que tenham contempladas demandas produtivas como assistenciais, interferindo nas condições e possibilidades de autonomia dos assentados.

As intervenções do Estado não se tornam apenas medidas de apoio para dar condições sociais mínimas, mas também para estimular o desenvolvimento rural mediante a atuação de seus órgãos. Em termos operacionais, a disponibilidade de terra, as condições e os estímulos da organização comunitária são essenciais para a implementação e o reconhecimento de um projeto de assentamento, mas não se restringem à concretização das relações (econômicas, sociais, políticas) das respectivas famílias assentadas, pois sem a conquista da terra, as novas relações sociais não podem se materializar no espaço (FABRINI, 2002).

O que se evidencia é o caráter identitário que se refere à intitulação quanto às modalidades de projetos de assentamento, alinhado ao grau de participação de órgãos nas três esferas (municipais, federais e estaduais), os quais, por sua vez, nos trâmites administrativos, têm seu tempo de atuação distinto conforme as peculiaridades jurídicas de cada projeto. Além disso, as etapas das fases de reconhecimento e implementação pelo INCRA, até serem considerados o assentamento consolidado, o efetivo cadastro das famílias no SIPRA e seus respectivos títulos, levam um tempo. Nesse contexto, as oportunidades de inserção ou não em contratos de ATER e/ou de outras políticas públicas agrícolas ou sociais nos respectivos assentamentos têm seus limites.

A importância da trajetória institucional de órgãos de fomento agrário e das políticas públicas de apoio à agricultura familiar vem se transformando e tornando-se essencial para estimular a sobrevivência das famílias no campo. Como tratado por Mattei (2007), o PAA, em sua finalidade, 
instiga os agricultores a produzirem em pequenas quantidades. Os que estão enfrentando dificuldades para agregar valor à produção são incentivados por meio de mecanismos de comercialização nos seus próprios locais de origem. Assim, conforme Grisa e Schneider (2014), com a criação do PAA se abriu uma "janela de oportunidades", gerando aprendizados para a construção de novas ações.

Em estudo realizado por Maia e Ferrante (2014) sobre a relação do PAA em assentamentos, revelou-se que o acesso ao Programa está para além de uma nova oportunidade de mercado por promover e melhorar a autoestima e a liberdade dos assentados. Contudo, ressalta-se que por se tratar de uma política envolvendo diversos agentes e instituições, a ausência de informação e de conhecimento sobre o processo e as possibilidades de inserção ao programa ainda limita o acesso dos assentados. Nesse sentido, sobre a análise das modalidades do PAA, constatou-se que a organização da comunidade em formas coletivas, como cooperativas e associações, possibilita um dinamismo maior para a inserção e a manutenção de modo positivo no PAA. Para as autoras (2014), ela estimula o desenvolvimento de novos modos de vida tanto na comunidade como regionalmente.

Em Santa Catarina, sobre o acesso ao PAA pelos projetos de assentamentos, foram encontrados 243 contratos, dos quais 237 (97,5\%) são na modalidade PA, quatro (1,7\%) são PRB e dois $(0,8 \%)$ PE, distribuídos em 21,6\% dos assentamentos no Estado. Esses números são baixos perante a quantidade de famílias por região, chegando a aproximadamente $6,46 \%$ de famílias assentadas no Oeste, $3,7 \%$ no vale do Itajaí, menos de $1 \%$ no Norte e na região Serrana, e sem contemplação alguma para os assentamentos da grande Florianópolis e do Sul.

Em relação ao acesso ao PAA em assentamentos catarinenses e no território nacional, temse como premissa a inserção do produtor, do assentado e dos demais grupos, conforme marco legislatório, na produção e na comercialização, investindo-se na capacidade de melhoria da organização local, em cooperativas e/ou associações. No entanto, o acesso efetivo deles esbarra no processo burocrático e sistêmico das exigências para a adesão a determinadas políticas públicas, cujo principal público tem dificuldades de acesso em virtude, entre outras situações, da ausência de informação quanto aos respectivos programas, além de limitações na adequação da documentação necessária e na assistência técnica para a produção e a gestão da propriedade, o que dificulta a sua participação (CASTRO; PEREIRA, 2017; SAMBUICHI et al., 2019).

Evidentemente, não são desafios restritos aos assentados, mas são intensificados a esse grupo em virtude do posicionamento e da concepção da política de reforma agrária, ainda incipiente em ações que proporcionam o impulso enquanto política social e produtiva, chegando de fato às heterogeneidades das modalidades de projetos de assentamentos. Fornecer políticas de fomento à 
produção é essencial ao enfrentamento dos desafios produtivos específicos dos assentamentos, assim como, acima de tudo, vincular a elas a compreensão de que fazem parte do conjunto de direitos sociais para a efetiva emancipação socioprodutiva das famílias assentadas.

\section{Figura 3 - Distribuição territorial dos assentamentos rurais nas mesorregiões catarinenses e acesso deles ao PAA e à ATER}

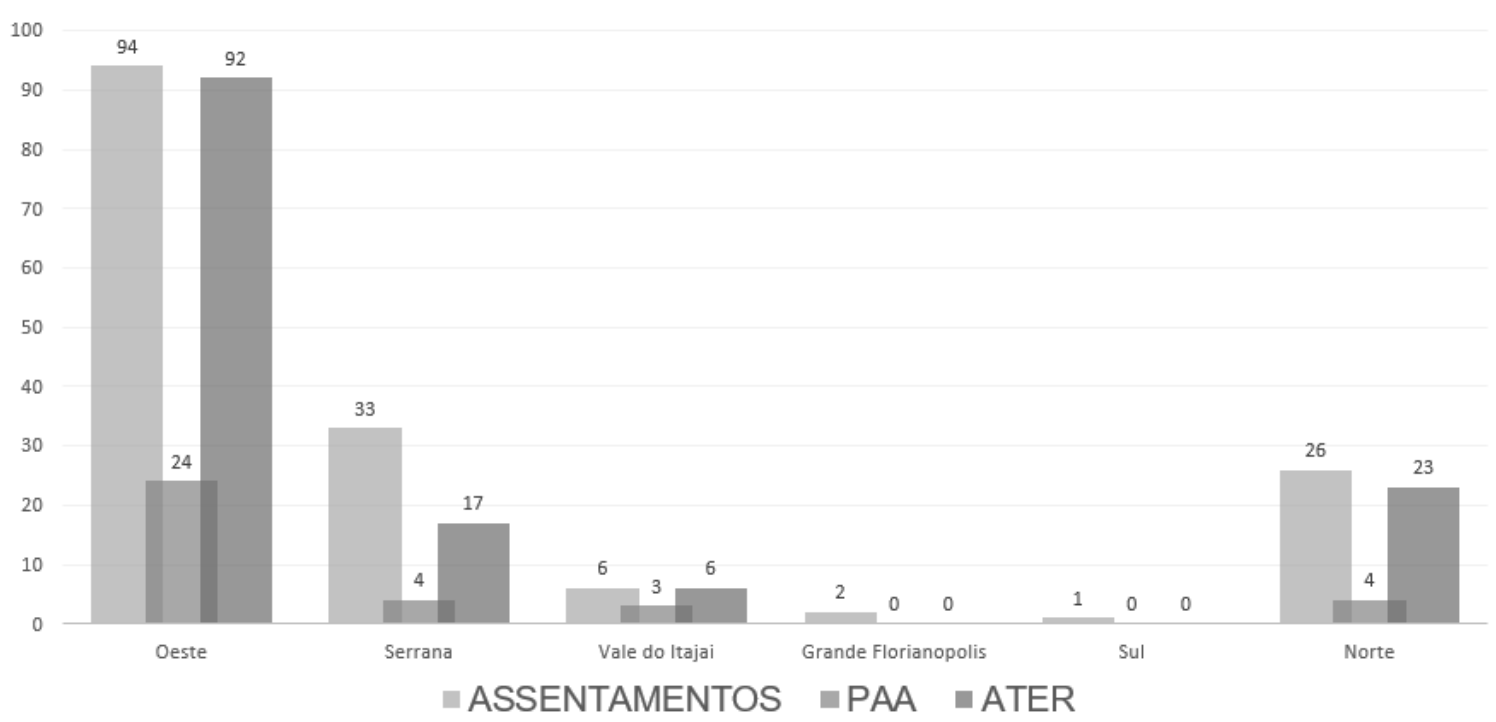

Fonte: Relatórios da Diretoria de Obtenção de Terras e Implantação de Projetos de Assentamento (BRASIL, 2020). Elaborada pelos autores (2020).

Nesta pesquisa, ficou evidenciada a centralização dos contratos de ATER e PAA em três tipos de projetos. Com referência aos contratos de ATER, em nível estadual, foram contemplados 138 assentamentos, sendo que apenas um está classificado como Projeto de Reassentamento de Barragens na modalidade II. Os demais 137 (99,3\%) são todos da modalidade I, tradicional de PA Federal. Com referência ao Programa de Aquisição de Alimentos, contempla 35 assentamentos no Estado, sendo 31 (88\%) na modalidade I PA, dois PRB e dois PE, correspondendo a 6\% em cada classificação de projeto.

Ademais, destaca-se ainda a distribuição de hectares no território catarinense como um campo de futuras explorações em aspectos fundiários e no contexto histórico e econômico, que se fez presente nesta discussão. Sobre a disponibilidade para projetos de reforma agrária, o Oeste possui o maior número de projetos $(58,0 \%)$, famílias $(69,9 \%)$ e território $(60,6 \%)$, porém no âmbito estadual apresenta a menor média de hectare por família (18,08ha/família). Já os assentamentos da grande Florianópolis e do Sul contam com a menor quantidade de projetos e com a maior média de área por família do Estado, seguindo respectivamente a ordem de 82,87 hectares/família e 53,46 
hectares/família, muito superior à média estadual $(20,84)$. Também são os que não contemplam nenhum projeto de ATER e PAA.

Constatou-se, ainda, a distribuição desigual dentro do território em relação ao acesso às políticas públicas (ATER e PAA), à estrutura fundiária e às modalidades de projetos, sendo que nestas duas últimas a decorrência tende a estar atrelada às peculiaridades de cada mesorregião e ao perfil das modalidades de projetos. Já em relação à ATER e ao PAA, aponta-se a centralização em núcleos de assentamentos integrando aspectos referenciados neste estudo como desafios encontrados pelas comunidades para a estruturação conforme os modos de organização produtiva exigidos pelos programas governamentais.

Em Santa Catarina, conforme ressaltado por Mattei (2007), no início da implementação do PAA, evidenciou-se a melhoria da qualidade de vida, além de oportunidades produtivas e de comercialização a partir do programa, principalmente em locais onde existiam movimentos sociais organizados que representavam as finalidades econômicas e sociais que a política almeja. Situação delicada, pois onde não se encontram organizações ou onde elas são ainda incipientes administrativamente, a tendência é que haja mais dificuldades de acesso.

Outro aspecto é a distribuição em blocos para a atuação de ATER no Estado, como evidenciado por Louzada (2020), que direcionava a partir dos critérios de cadastro os beneficiários reconhecidos como titulares da política, excluindo as famílias que ainda estavam com pendências na regularização fundiária e/ou em processos administrativos, jurídicos e políticos de atribuição do INCRA, sob a coordenação da Superintendência Regional.

Importante ressaltar que, por vezes, a menção dos contratos de ATER não significa garantia de que mesmo havendo a ação dessa assistência técnica ocorra a produtividade e a comercialização agropecuária, haja vista outros fatores não avaliados especificamente em cada projeto catarinense, mas já discorridos em termos do cenário nacional, como, por exemplo, a viabilidade produtiva, seja por manejo e fertilidade das terras disponíveis ou infraestrutura de armazenagem, processamento e ou comercialização dos produtos. Também as dificuldades no acesso às políticas públicas de saúde, educação e infraestrutura básica, como energia, água e saneamento, cuja disponibilidade é requisito básico de viabilidade dos projetos de assentamento. Sem explicitar mais detalhadamente, inclui-se, ainda, um conjunto heterogênico de desigualdades internas dos próprios assentamentos, presentes nas subjetivas da trajetória individual e familiar e da capacidade de inserir-se na comunidade e nas funções produtivas.

Não se pode afirmar que a ausência de assentamentos atendidos pela ATER ou mesmo pelo PAA impossibilite outras formas de sobrevivência e renda nessas comunidades. Almeida, Amin e 
Souza Filho (2009) destacam que a assistência técnica, muitas vezes, é meramente tecnificada, sem englobar questões assistenciais ou ainda dos saberes populares assentados, mas contempla o leque de problemática e limitação da implementação e do controle de recursos humanos e financeiros da reforma agrária. Por isso, trata-se de um trabalho multidisciplinar, complexo, estruturado, que possibilita a consolidação de ações, alinhando-se às possibilidades e exigências dos partícipes (Estado e comunidade).

No contexto da questão agrária, os assentamentos são núcleos estratégicos de distribuição fundiária, difusores de conflitos territoriais e sociopolíticos, um "reconhecimento" estatal que em seu processo de formação e consolidação ressignifica na resistência da população e nas interferências - atuantes ou não - do Estado (BERGAMASCO, 1997; LEITE et al., 2004).

Sobre a conjuntura do panorama dos projetos de assentamentos no estado catarinense e o acesso das famílias assentadas por meio de políticas públicas como as analisadas (PAA e ATER), registram-se algumas questões estruturais que complementam a análise e inferem sobre os dados disponibilizados pelo INCRA, haja vista que o órgão informa as fases de implementação dos respectivos projetos, embora apresente divergências nos dados divulgados para as afirmações sobre assentamentos e famílias com titularidade efetiva da terra, ou seja, que já estejam com o processo de regularização fundiária consolidado, viabilizando, em certo grau, a inserção em determinados programas para fomento ao segmento agrário. De maneira oposta, vigoram impasses e limitações legais, administrativas e burocráticas para enquadramento em determinadas políticas.

Além do mais, é preciso considerar o período temporal de análise deste estudo, que remete, como já citado, à limitação de dados publicados de programas vinculados à agricultura familiar, como a reforma agrária e fundiária, em decorrência de reformas do Estado que têm limitado a atuação de seus órgãos seja administrativamente ou político-institucionalmente, por meio de ações efetivas do governo a partir de 2016. Incluem-se nesse cenário as políticas sociais em geral, que sofrem cortes significativos de recursos.

Esse conjunto de fatores, por sua vez, reflete na aplicação de recursos em programas como os analisados. É notório na pesquisa de Louzada (2020), que abordou o período de 2012-2017 da ATER em Santa Catarina, o grau de influência das atuações em governos que visualizam a inserção de políticas públicas como pilar para um conjunto de melhorias socioeconômicas a governos que articulam um processo de desmonte por ausência de pautas que envolvem a conjuntura da questão e a reforma agrária brasileira. O autor (2020, p. 66) aponta que após 2015 “[...] a ATER voltada aos assentados da reforma agrária (e outros públicos) tem um desfecho de desarticulação, abandono e falta de prioridade estatal em atender as suas demandas". 
Ainda, sobre a ATER, Peixoto (2014) menciona nove formas de financiamento de suas atividades e apresenta uma reflexão quanto ao desafio de compor uma base orçamentária e de gestão à prestação do serviço e distribuição no território brasileiro. A participação de instituições públicas e privadas para o provimento era a esperança de "[...] minorar a histórica deficiência de financiamento desse serviço" (CASTRO; PEREIRA, 2017, p. 24). Entretanto, ainda assim, trata-se de uma agenda atuante do Estado, com disponibilidade de orçamento para firmar acordos que atendam aos propósitos e às carências.

O baixo engajamento para suprir minimamente uma política significativa e consolidada como a ATER faz parte também da triste realidade do PAA. Nos últimos anos, têm sido observados os cortes orçamentários e a diminuição de beneficiários, alinhando-se também com a extinção do Ministério do Desenvolvimento Agrário (MDA), que passou a vigorar com função e orçamento de secretaria (SAMBUICHI et al., 2019).

Cabe considerarmos como reflexão que, ao tratarmos de assentamentos rurais, a complexidade das análises deve perpassar o contex to qualitativo de assentamentos reconhecidos e títulos de terras disponibilizados em determinados períodos governamentais. Significa, sobretudo, trazer ao debate as dimensões técnicas e legais até as dimensões estruturais, políticas e socioculturais que constituem o espaço desses assentamentos, de modo que a diversidade de experiências, a pluralidade de reprodução social e produtiva, por mais que o normativo das relações entre as famílias assentadas e o Estado sigam um rito e suas formalizações gerem problemas comuns, requeiram políticas públicas pertinentes, com consolidações que possam instigar a representatividade, o amadurecimento e a alteridade às comunidades.

\section{CONSIDERAÇÕES FinAIS}

A questão agrária brasileira revela as contradições, os conflitos e, sobretudo, a riqueza de recursos naturais no território e a diversidade de experiências socioculturais e produtivas possíveis no mesmo campo de disputa política e ideológica, que ocasiona os problemas agrários, atinge de modo distinto a sociedade, seus meios de sobrevivência e valores sociais e produtivos que, na coexistência de sentidos divergentes e ao mesmo tempo complementares sobre o significado do patrimônio terra, retornam ao debate corrente sobre a temática e as transformações pelas lutas e resistências pela terra. 
Diante da diversidade de formas de organização, de modos de produção e de possibilidades de acesso a mercados aos assentamentos, inferem-se os limites não só impostos pelas políticas públicas, como os que legitimam a existência formal de projetos de assentamentos para acesso a elas.

Ao traçar o panorama dos assentamentos rurais em Santa Catarina, como resultados foram constatados, a partir dos dados do INCRA (BRASIL, 2020), o registro de 162 projetos de assentamentos, o que representa 1,72\% dos assentamentos do País, com 5.033 famílias assentadas, representando 0,52\% do Brasil, distribuídos nas seis mesorregiões do Estado. Constataram-se 138 contratos de ATER e 243 contratos de PAA, distribuídos em 21,6\% dos assentamentos. As mesorregiões da grande Florianópolis e do sul do Estado contam com a menor quantidade de projetos e com a maior média de área por família, não possuindo projetos contemplados com a ATER e o PAA. Conclui-se que há uma distribuição desigual dentro do território em relação ao acesso às políticas públicas (ATER e PAA).

Cabe, em estudos futuros, expandir a análise em prol de demonstrar o pluralismo sociocultural presente nas peculiaridades das comunidades, em suas respectivas modalidades de assentamentos institucionalizadas, sobretudo ante as adversidades da QA e das diretrizes que legitimam os beneficiários de determinadas políticas públicas em prol de identificar as organizações de resistência nos espaços sociais e produtivos, condicionados e construídos em projetos de assentamentos.

\section{Agradecimentos}

Trabalho vinculado à linha e pesquisa Desenvolvimento e Gestão Social do Programa de PósGraduação em Desenvolvimento Socioeconômico (PPGDS) da Universidade do Extremo Sul Catarinense (UNESC). Inserido no Grupo de Pesquisa em desenvolvimento socioeconômico, agricultura familiar e educação do campo (Gidafec). Os autores agradecem à Fundação de Amparo à Pesquisa e Inovação do Estado de Santa Catarina, (FAPESC) e a Coordenação de Aperfeiçoamento de Pessoal de Nível Superior, CAPES pela concessão de bolsa de mestrado para a primeira autora. Também agradecem aos (as) pareceristas anônimos que contribuíram com sugestões relevantes para a versão final do artigo. Afirma-se que não há conflitos de interesse na publicação deste artigo e que ele contém interpretação analítica dos dados de responsabilidade exclusiva dos autores. 


\section{REFERÊNCIAS}

ALMEIDA, Mário B.; AMIN, Mário M.; SOUZA FILHO, Theophilo A. de. Reforma Agrária e modernização da agricultura: contribuições para a avaliação da experiência brasileira. Revista de Administração e Negócios da Amazônia, [S.1.], v. 1, n. 1, p. 32-50, 2009. Disponível em: https://www.periodicos.unir.br/index.php/rara/article/view/7. Acesso em: 09 fev. 2021.

BERGAMASCO, Sônia M. P. P. A realidade dos assentamentos rurais por detrás dos números. Estudos Avançados, [S.1.], v. 11, n. 31, p. 37-49, 1997. ISSN 1806-9592. Disponível em: http://dx.doi.org/10.1590/S0103-40141997000300003. Acesso em: 09 fev. 2021.

BRASIL. Lei n ${ }^{\circ}$ 4.504, de 30 de novembro de 1964. Dispõe sobre o Estatuto da Terra, e dá outras providências. Diário Oficial da União. Brasília, DF, 30 nov. 1964. Disponível em: http://www.planalto.gov.br/ccivil_03/leis/14504.htm. Acesso em: 09 fev. 2021.

BRASIL. [Constituição (1988)]. Constituição da República Federativa do Brasil de 1988. Brasília, DF: Presidência da República, 1988. Disponível em: http://www.planalto.gov.br/ccivil_03/constituicao/constituicao.htm. Acesso em: 18 mar. 2020.

BRASIL. Lei no 8.629, de 25 de fevereiro de 1993. Dispõe sobre a regulamentação dos dispositivos constitucionais relativos à reforma agrária, previstos no Capítulo III, Título VII, da Constituição Federal. Diário Oficial da União. Brasília, DF, 26 fev. 1993. Disponível em: http://www.planalto.gov.br/ccivil_03/leis/18629.htm. Acesso em: 09 fev. 2021. BRASIL. Lei nº 10.696, de 02 de julho de 2003. Dispõe sobre a repactuação e o alongamento de dívidas oriundas de operações de crédito rural, e dá outras providências. Diário Oficial da União. Brasília, DF, 3 jul. 2003. Seção 1, p. 1. Disponível em: http://www.planalto.gov.br/ccivil_03/LEIS/2003/L10.696.htm. Acesso em: 19 mar. 2020.

BRASIL. Ministério do Desenvolvimento Agrário - MDA. Instrução normativa Incra nº 15, de 30 de março de 2004. Dispõe sobre o processo de implantação e desenvolvimento de projetos de assentamento de reforma agrária. Diário Oficial da União. Brasília, DF, 5 abr. 2004, n. 65, seção 1, p. 148. Disponível em: http://www.incra.gov.br/institucionall/legislacao--/atos-internos/instrucoes/file/167-instrucao-normativa-n15-30032004. Acesso em: 19 mar. 2020.

BRASIL. Lei n ${ }^{\circ} 11.947$, de 16 de junho de 2009. Dispõe sobre o atendimento da alimentação escolar e do Programa Dinheiro Direto na Escola aos alunos da educação básica; altera as Leis nº 10.880, de 9 de junho de 2004, 11.273, de 6 de fevereiro de 2006, 11.507, de 20 de julho de 2007; revoga dispositivos da Medida Provisória $n^{\circ}$ 2.178-36, de 24 de agosto de 2001, e a Lei no 8.913, de 12 de julho de 1994; e dá outras 
providências. Diário Oficial da União. Brasília, DF, 17 jun. 2009. Disponível em: http://www.planalto.gov.br/ccivil_03/_ato2007-2010/2009/lei/111947.htm. Acesso em: 19 mar. 2020. BRASIL. Lei n ${ }^{\circ}$ 12.188, de 11 de janeiro de 2010. Institui a Política Nacional de Assistência Técnica e Extensão Rural para a Agricultura Familiar e Reforma Agrária - PNATER e o Programa Nacional de Assistência Técnica e Extensão Rural na Agricultura Familiar e na Reforma Agrária - PRONATER, altera a Lei $\mathrm{n}^{\circ}$ 8.666, de 21 de junho de 1993, e dá outras providências. Diário Oficial da União. Brasília, DF, 11 jan. 2010. Disponível em: http://www.planalto.gov.br/ccivil_03/_ato2007-2010/2010/lei/112188.htm. Acesso em: 19 mar. 2020.

BRASIL. Decreto n 7.775 , de 04 de julho de 2012. Regulamenta o art. 19 da Lei $n^{\circ} 10.696$, de 2 de julho de 2003, que institui o Programa de Aquisição de Alimentos, e o Capítulo III da Lei no 12.512, de 14 de outubro de 2011, e dá outras providências. Diário Oficial da União. Brasília, DF, 05 jul. 2012. Disponível em: http://www.planalto.gov.br/ccivil_03/_ato2011-2014/2012/decreto/d7775.htm. Acesso em: 19 mar. 2020.

BRASIL. Instituto Nacional de Colonização e Reforma Agrária - INCRA. Relatórios da Diretoria de Obtenção de Terras e Implantação de Projetos de Assentamento. Atual. 2020. Disponível em: http://www.incra.gov.br/sites/default/files/uploads/reforma-agraria/questao-agraria/reformaagraria/projetos_criados-geral.pdf. Acesso em: 02 mar. 2020.

CARVALHO, Horácio M. de. Uma ressignificação para a reforma agrária no Brasil. In: STEDILE, João P. (Org.). A questão agrária do Brasil: debate sobre a situação e perspectiva da reforma agrária na década de 2000. 1. ed. São Paulo: Expressão Popular, 2013.

CASTRO, César N. de; PEREIRA, Caroline N. Agricultura Familiar, Assistência Técnica e Extensão Rural e a Política Nacional de ATER. Texto para Discussão n. 2343. Rio de Janeiro: IPEA, 2017. Disponível em: http://repositorio.ipea.gov.br/bitstream/11058/8114/1/td_2343.PDF. Acesso em: 09 fev. 2021.

FABRINI, João E. O projeto do MST de desenvolvimento territorial dos assentamentos e campesinato. Terra Livre, São Paulo, ano 18, n. 19, p. 75-94, jul./dez. 2002. Disponível em: https://www.agb.org.br/publicacoes/index.php/terralivre/article/view/159. Acesso em: 12 fev. 2021. FERNANDES, Bernardo M. Acampamento. In: CALDART, Roseli S. et al. (Orgs.). Dicionário da Educação do Campo. São Paulo: Expressão Popular, 2012, p. 26-27.

FERNANDES, Bernardo M. Questão agrária. São Paulo: Cortez, 2001.

FERREIRA, Brancolina. Estratégias de intervenção do Estado em áreas de assentamento: as políticas de assentamento do Governo Federal. In: MEDEIROS, Leodilde et al. (Orgs.) Assentamentos rurais: uma visão multidisciplinar. São Paulo: Editora da Universidade Estadual Paulista, 1994, p. 29-47.

FLICK, Uwe. Introdução à pesquisa qualitativa. 3. ed. Porto Alegre: Artmed, 2009. 
GIL, Antônio C. Como elaborar projetos de pesquisa. 5. ed. São Paulo: Atlas, 2014.

GRISA, Cátia; SCHNEIDER, Sérgio. Três Gerações de Políticas Públicas para a Agricultura Familiar e Formas de Interação entre Sociedade e Estado no Brasil. RESR, Piracicaba, v. 52, Supl. 1, p. S125-S146, 2014. Disponível em: http://www.scielo.br/pdf/resr/v52s1/a07v52s1.pdf. Acesso em: 20 maio 2020.

GUANZIROLI, Carlos et al. (Orgs.). Principais fatores que afetam o desenvolvimento dos assentamentos de reforma agrária no Brasil. Projeto de cooperação técnica INCRA/FAO. Brasília, DF: INCRA, 1999.

LEITE, Sergio P. Assentamento Rural. In: CALDART, Roseli S. et al. (Orgs.). Dicionário da Educação do Campo. São Paulo: Expressão Popular, 2012, p. 110-114.

LEITE, Sergio P. et al. Impactos dos assentamentos: um estudo sobre o meio rural brasileiro. São Paulo: Editora da Unesp; Brasília: Nead, 2004.

LOUZADA, José A. Implementação da Política de Assistência Técnica e Extensão Rural nos Assentamentos de Reforma Agrária em Santa Catarina/Brasil: Uma análise a partir dos instrumentos da ação pública. Revista Raízes, Campina Grande, v. 40, n. 1, p.63-83, jan./jun. 2020. Disponível em: https://doi.org/10.37370/raizes.2020.v40.583. Acesso em: 20 maio 2020.

MAIA, Priscila de O.; FERRANTE, Vera L. B. S. PAA em assentamentos rurais: novos modos de vida? Retratos de Assentamentos, [S.1.], v. 17, n. 1, p. 245-260, 2014. DOI: 10.25059/2527

2594/retratosdeassentamentos/2014.v17i1.162. Disponível em: https://retratosdeassentamentos.com/index.php/retratos/article/view/162. Acesso em: 14 mar. 2020. MARTINS, Heloisa H. T. de S. Metodologia qualitativa de pesquisa. Educação e Pesquisa, São Paulo, v. 30, n. 2, p. 289-300, maio/ago. 2004. Disponível em: https://www.scielo.br/pdf/ep/v30n2/v30n2a07.pdf. Acesso em: 13 fev. 2020.

MARTINS, José de S. O Cativeiro da terra. 2. ed. São Paulo: Hucitec, 1981.

MATTEI, Lauro F. Programa de Aquisição de Alimentos da agricultura familiar (PAA): percepções de atores sociais do estado de Santa Catarina. In: CONGRESSO BRASILEIRO DE ECONOMIA, ADMINISTRAÇÃO E SOCIOLOGIA RURAL, 45., 2007, Londrina. Anais... Londrina, PR: Sober, 2007. MATTEI, Lauro F. Teses favoráveis e contrárias à reforma agrária brasileira no limiar do século XXI. Revista da ABRA, [S.1.], v. 35, p. 93-113, 2014.

MEDEIROS, Leonilde et al. (Orgs.). Assentamentos rurais: uma visão multidisciplinar. São Paulo: UNESP, 1994.

NEVES, Delma P. Assentamentos rurais: reforma agrária em migalhas. Niterói: EDUFF, 1997. 
PEIXOTO, Marcus. Mudanças e desafios da extensão rural no Brasil e no mundo. In: BUAINAIN, Antônio M. et al. O mundo rural no Brasil do século 21: a formação de um novo padrão agrário e agrícola. Brasília: Embrapa, 2014.

SAMBUICHI, Regina H. et al. Programa de Aquisição de Alimentos e Segurança Alimentar: modelo lógico, resultados e desafios de uma política pública voltada ao fortalecimento da agricultura familiar. Texto para Discussão n. 2482. Rio de Janeiro: IPEA, 2019. Disponível em: http://repositorio.ipea.gov.br/bitstream/11058/9319/1/TD_2482.pdf. Acesso em: 09 fev. 2021. SAQUET, Marcos A. Por uma abordagem territorial. In: SAQUET, Marcos A.; SPOSITO, Eliseu S. Território e territorialidades: teorias, processos e conflitos. São Paulo: Expressão Popular, 2009, p. 7394.

STÉDILE, João P. A questão agrária no Brasil. São Paulo: Expressão Popular, 2005.

WANDERLEY, Maria de N. B. A valorização da agricultura familiar e a reivindicação da ruralidade no Brasil. Desenvolvimento e Meio Ambiente, Curitiba, n. 2, p. 29-37, jul./dez. 2000. 